\title{
Mothers and Premature Infants' Emotional Interactions in a Neonatal Infant Care Unit: Case Studies
}

\author{
Ligia M.C.C. Tropiano \\ Master in Developmental Disabilities U. Presbiteriana Mackenzie, Brazil \\ Geraldo A. Fiamenghi-Jr \\ $\mathrm{PhD}$ in Psychology FAAT, Brazil \\ Silvana M. Blascovi-Assis \\ Doctor in Physical Education U. Presbiteriana Mackenzie, Brazil
}

Doi: 10.19044/esj.2017.v13n36p85 URL:http://dx.doi.org/10.19044/esj.2017.v13n36p85

\begin{abstract}
The aim of this study was to describe the ways premature infants and their mothers emotionally interact in the first weeks of their lives. In order to understand the intersubjective dyadic interaction between mother and premature infant, a qualitative and descriptive approach to research has been adopted. Four dyads comprised of primiparae women and their newly-born premature infants took part in the study. The babies were born prematurely after 28 to 35 weeks of gestation and admitted to the neonatal intensive care unit (NICU). Data was collected filming the first dyadic interaction with infant in the mother's arms, lasting between 15 to 30 minutes. After that first registry, dyadic behaviors between mother and baby were described and categorized following the intersubjective categories suggested by Fiamenghi (1999) and Fiamenghi et al. (2010). Results showed that dyads display positive emotions, with infants' behaviors falling into the categories of negotiation, interaction and emotional curiosity; as well as a low frequency of negative behaviors. The outcome of this research reinforces the need to adopt a humanizing approach to prematurely born infants and their mothers in NICU, as well as training and awareness of the whole multidisciplinary team that deals with them.
\end{abstract}

Keywords: Prematurity, intersubjectivity, infant behavior, maternal behavior, NICU staff

\section{Introduction}

The World Health Organization Report estimates around 15 million premature births around the world, over 10\% of the total (WHO, 2012 a). 
Alongside the risky medical consequences of premature birth, studies also show social consequences, due to abandon and high cost of postnatal care (Linhares, Bordim \& Jorge, 2001; Rodrigues et al, 2011). High prevalence of prematurity brings important social and economic expenses, such as growing demand for neonatal intensive care units and costs of attention at short term, and in long term, caring for individuals suffering from permanent physical and mental damages caused by prematurity (Silveira et al, 2013). In developing countries, such as Brazil, the establishing of adequate caring parameters to newborns is one of the challenges to reduce infant mortality, as $70 \%$ of infant deaths are caused by neonatal complications. Prematurity is defined by parameters in medical exams (clinical and ultrasonography data) as well as infant's anatomic assessment (especially weight and height) (Wiese, 2009). Preterm infants born under $1500 \mathrm{~g}$ of weight are a high-risk group to presenting developmental problems (Linhares, 2004). Usually, the lower the gestational age and weight at birth, the worst the prognosis, as most frequent health issues may be apnea, anemia, bronchopulmonary dysplasia, intraventricular hemorrhage, asphyxiation, pneumomediastin, and transient tachypnea. Premature newborns are more prone to present cognitive disabilities, worst general performance, and behavioral difficulties (Mellier, 1999). Neurological conditions at birth and infant's family environment will significantly interact, attenuating or aggravating the starting of intercurrences (Brazelton, 1992).

Traditionally, Psychology has been concerned with the cognitive functioning, isolating affective aspects, even neglecting them as a substrate of human condition. More recently, researchers began to admit that infants were capable of smiling, being that not a reflex act, although not being able to communicate or to behave intentionally. In fact, Psychology believed that newborns presented a limited repertoire of emotional responses, a diffuse emotional excitement, not to be considered an emotion (Fiamenghi-Jr, 1999). Studies on newborns' social and affective development leave no doubt about infants' capacity to intentionally react to adults, (Trevarthen, 1979; Brazelton, 1981; Tronick, 2007; Trevarthen, 2004; Fiamenghi-Jr et al, 2010). Recognition of infants' innate intersubjectivity presents a new paradigm to understand human interactions and their emotional regulation (Trevarthen, 1998; Trevarthen \& Aitken, 2001). An important concept concerning intersubjectivity is a neural based system for non-verbally mediated social abilities, named intrinsic motivational formation (Aitken, 2008). We are now capable of considering the infant as an active, coherent and motivated being, ready to establish relations with the human environment from birth, especially, but not only, with the mother (Fiamenghi-Jr, 2010). Gender differences, as well as mirror interactions have been the center of 
observations and systematic studies (Fiamenghi-Jr, 1999; Wanderlind et al, 2006), although focusing on full-term infants.

Many studies have shown the premature newborn as an able and active partner in interactions with the environment (Wendland, 2001; Wiese, 2009). On the other hand, some studies state that prematurity may affect early orientation behavior, infants' relations to other people and objects, as well as the regulation of attentional states and habituation to repetitive perceptual events, suggesting that the premature infant does not present the same interactive competences as the full-term ones, being less sensitive and reactive to external stimuli (Als, 1994; Charavel, 2000).

Although premature infants present low weight and development immaturity, they have mechanisms of expression of their internal experiences. Staff that deal with premature infants know that they are able to manifest pleasure, pain, to search or to avoid human contact. Premature infants' fragility and support needs impose refined clinical decisions that must be based on knowledge of their emotional development. Intensive care aiming the premature infant's survival, as well as all the psychological perspectives on their emotional development elicits questions, especially whether prematurity may alter, or interfere in the quality of intersubjective communication.

Thus, the present study aimed to observe and describe emotional interactions of premature infants in their first contact with their mothers, while still in neonatal intensive care unit (NICU), to analyze the innate ability to communicate their intersubjective states.

\section{Method}

A qualitative descriptive approach was used to understand motherpremature infant dyads. 4 dyads, primiparae mothers and their premature infants (28 to 35 gestational age), 2 males, 2 females, attended at a NICU of a public hospital in São Paulo metropolitan area, Brazil, participated on this study. This specific NICU follows humanization procedures when dealing with premature infants, such as the kangaroo care, and daily visits of the parents. Dyads are described below:

- D1: mother (M1) and daughter (B1), 34 weeks gestational age at birth, Apgar scores 8, 9, 9, filmed when infant was 5 days old;

- D2: mother (M2) and son (B2), 30 weeks gestational age at birth, Apgar scores 8, 10, 10, filmed when infant was 6 days old;

- D3: mother (M3) and son (B3), 28 weeks gestational age at birth, Apgar scores 9, 9, 9, filmed when infant was 4 days old;

- D4: mother (M4) and daughter (B4), 32 weeks gestational age at birth, Apgar scores 7, 8, 8, filmed when infant was 3 days old 
After mothers signed the term of consent, and completed a questionnaire with demographic information, filming started, each session lasting 15 to 20 minutes, during the mother's first visit to her infant at NICU. The infant was placed in the mother's lap, or stayed in the incubator, and the camera was fixed at one meter in front of the dyad, to register mother and infant. Dyads behaviors were described and categorized, according to Fiamenghi-Jr (1999) e Fiamenghi-Jr et al. (2010).

\section{Results and Discussion}

Mothers' ages varied from 20 to 30 years, all of them primiparae, and submitted to caesarean section. Two of them were married, one was a student, and none worked, all belonging to low class, according to Brazilian Economic Classification Criteria (ABEP, 2010). After being released from hospital, mothers came every day to stay with their infants, arriving in the morning, spending all day at the NICU, and returning home around 6:00 p.m. None of them were allowed to sleep in the hospital and meals were served by the institution (lunch, afternoon snack and dinner).

Each dyad' interactions are described and discussed below.

\section{Dyad 1 (M1; B1)}

Mother seems to be at ease during filming, eager to interact with her 5-day-old daughter. She kisses her, and caresses her head. The infant responds by moving to a comfortable position in her mother's lap. Infant keeps her eyes closed, with a relaxed face, only opens the eyes as a response to her mother's voice or touch. Mother smiles when looking at her daughter, and keeps caressing her, searching the best position for the infant. Infant searches her mother's breast and changes to an uncomfortable position and the mother immediately and calmly moves her. Mother chats with her daughter, who looks at her, showing interest, with curiosity. Suddenly, the nurse intervenes to reposition the oximetry monitoring sensor. Infant cries, showing irritation as the contact with her mother is broken. When the nurse finishes the procedure, mother moves the daughter to a comfortable position; infant closes her eyes, again opening them only when the mother speaks.

The recording shows many emotional categories: curiosity (infant in relation to the mother), irritation (when the interaction is broken as the nurse fixes the oximeter), sympathy (mother towards the infant and vice-versa), and constant interactions on the part of the mother in relation to her infant, as well as synchronic responses from the infant to maternal contact. Those results are in accordance to Fiamenghi-Jr (1999), explaining the importance of synchrony, timing and empathy of feelings in mother-infant interactions.

The infant seems aware of the other and able to distinguish between her mother's contact and another person's (the nurse). As Trevarthen (2004) 
and Fiamenghi-Jr et al (2010) explain, infants are eager to share experiences, and it can be noted that premature infants also show emotional communication, suggesting that intersubjective motives guide the interactions (Trevarthen, 2001).

\section{Dyad 2 (M2; B2)}

Infant (6-day-old) was placed in kangaroo position. Mother smiles during preparation e positioning of her infant and talks to him all the time. She has her eyes fixed on him, holds his head, in a protective way. The infant keeps his eyes closed, showing a relaxed face, lifting his eyebrows, and smiles. The mother speaks and the infant smiles in response to his mother's voice. Noises intensify in the room (alarms from monitoring sensors). Infant frowns as if being annoyed, but the mother starts talking to her son, reassuring and caressing him. The infant immediately relaxes and seems to be comfortable again.

Although it might seem that this infant is less responsive, he does not refuse interaction, but is in a contented state. In fact, sympathy can be observed, as he smiles to his mother's speech, and even feeling reassured by the mother, when feeling distressed. (Fiamenghi-Jr et al, 2010).

\section{Dyad 3 (M3; B3)}

The mother looks at her 4-day -old son and smiles all the time, from the time he is taken from the incubator, until he is placed on her body in kangaroo position. She seems to feel proud and anxious to establish contact with her son. Differently from the other infants in this sample, the infant needs oxygen support, even while in his mother's lap. The mother doesn't seem to be bothered by the equipment, and is happy, smiling many times. The infant keeps his eyes closed, while being caressed by his mother, showing a relaxed expression. He opens his eyes and searches for the mother that immediately responds, smiling, talking and caressing him. The infant then looks around and closes his eyes, curling up against his mother's body.

This dyad showed interaction, and invitation, as proposed by (Fiamenghi-Jr, 1999; Fiamenghi-Jr et al, 2010), as well as sympathy, with synchronic answers from the mother to the infant and vice-versa (Trevarthen, 1998; 2004)

\section{Dyad 4 (M4; B4)}

The mother looks at her 3-day-old daughter, from the moment she is taken from the incubator until she is placed in kangaroo. The infant cries during the process but stops immediately when is in touch with the mother's body. The mother caresses the daughter, and holds her very tight against her body. The infant opens the eyes, searches for her mother's face, smiles, 
closes her eyes and curls up. After 10 minutes, the father arrives, and looks at the daughter, bends down and starts talking to the infant. She opens her eyes hearing her father's voice. Father and mother talk, and the infant opens her eyes, smiles and curls up.

Invitation and sympathy could be observed in this recording (Fiamenghi-Jr et al, 2010). Invitations are also observed, as well as sympathy.

A different element in this recording was the father's presence. It is important to note that the father plays a significant role concerning premature infants, supporting the mother, as well as security for the infant (Klaus, Kennell \& Klaus, 1996).

\section{Interactions}

Observing all dyads, it's possible to note invitations and interactions, although they do not last much. Fiamenghi-Jr (1999) explains that infants are engaged in repeating invitations to their interactive partners, aiming to engage them in interactions, but their attention span is not very large. Concerning this aspect, researchers show that mothers are more efficient in sustaining interactions with their infants (Fogel, 1988; Schermann, 2001; Trevarthen, 2001).

Relative to premature care, touch is fundamental as it is associated to comfort. For those mothers, care is more than a simple action; it is an acknowledgment of motherhood. Araújo and Rodrigues (2010) add that intention of being close to the premature infant is related to the recovery of its clinical status and faster weight gain. All the dyads in this sample had their first skin to skin contact during the recordings, due to prematurity. Because of that, they had been deprived of contact until the infants achieved clinical stability. Thus, dyads were eager to be together, and for the mothers, it meant a mark on prognosis of improvement in their infants.

\section{Conclusion}

The aim of this research was to describe how premature infants behave intersubjectively with their mothers in the first weeks of life. Therefore, the analysis of the recordings of the mother-infant dyads showed that even premature infants are able to engage in intersubjective exchanges.

It seems that the infants express positive emotions and are attuned to their mothers' invitations to interact, reflecting synchrony, timing, and empathy.

A limitation of this study was the small numbers of participants and the analysis of only one recording of each dyad. Nevertheless, results encourage the discussion of emotional issues of premature infants and their 
mothers in NICU settings, to be considered by staff dealing with that population.

\section{References:}

1. ABEP (Associação Brasileira de Empresas de Pesquisa). Brazilian economic classification criteria. 2010. Retrieved from http://www.abep.org/novo/Content.aspx?ContentID=301

2. Aitken, K. J. (2008). Intersubjectivity, affective neuroscience and the neurobiology of autistic spectrum disorders: A systematic review. Keio Journal of Medicine, 57(1), 15-36.

3. Als, H., Lawhon, G., Duffy, F. H., McAnulty, G. B., GibesGrossman, R., \& Blickman, J. G (1994) Individualized developmental care for the very low birth weight preterm infant. Journal of the American Medical Association, 272, 853-858.

4. Araújo, B. B. M., \& Rodrigues, B. M. R. D. (2010), Vivências e perspectivas maternas na internação do filho prematuro em Unidade de Tratamento Intensivo Neonatal. Revista Escola Enfermagem USP, 44(4), 865-72.

5. Brazelton, T. B. (1981). On becoming a family: The growth of attachment. New York: Delacorte Press/Seymour Lawrence.

6. Brazelton, T. B. (1992). Touchpoints: Your child's emotional and behavioral development. Birth to 3. New York: Da Capo Lifelong Books.

7. Charavel, M. (2000). Evolution de l'attitude des mères d'enfant prématuré et des mères d'enfant à terme en interaction avec leur bébé : une étude éthologique de la naissance à 6 mois. Psychiatrie de l'enfant, 43(1), 175-206.

8. Fiamenghi-Jr, G. A. (1999). Conversas dos bebês. [Infants conversations] São Paulo: Hucitec,

9. Fiamenghi-Jr, G. A., Vedovato, A. G., Meirelles, M. C., \& Shimoda, M. E. Mothers' interaction with their disabled infants: two case studies. Journal of Reproductive and Infant Psychology, 28(2), 191199, 2010.

10. Fogel, A. (1988). Cyclicity and stability in mother-infant face-to-face interaction: A comment on Cohn and Tronick. Developmental Psychology, 24(3), 393-395.

11. Klaus, M. H., Kennell, J., \& Klaus, P. H. (1996). Bonding: Building the foundations of secure attachment and independence. New York: Da Capo Press.

12. Linhares, M. B. M., Bordim, M. B. M., \& Jorge, S. M. (2001). Aspectos cognitivos e comportamentais na média meninice de 
crianças nascidas pré-termo e com muito baixo peso. Psicologia: Teoria e Pesquisa, 17(1), 49-57.

13. Linhares, M. B. M. (2004). Estresse, resiliência e cuidados no desenvolvimento de neonatos de alto risco. In Mendes, E. G. M., Almeida, A., \& Williams, L. C. A. (Eds), Temas em Educação Especial (Issues in Special Education] (pp. 315-324). São Carlos: EDUFScar.

14. Mellier, D. (1999) La prématurité: L’ouverture de problématiques nouvelles. Enfance, 1, 3-11.

15. Rodrigues, M. C. C.; Melo, R. R.; Silva, K. S.; \& Carvalho, M. L. (2011). Desenvolvimento cognitivo de prematuros à idade escolar. Cadernos de Saúde Pública, Rio de Janeiro, 27(6), 1154-1164.

16. Schermann, L. (2001). Considerações sobre a interação mãe-criança e o nascimento pré-termo. Temas em Psicologia (Sociedade Brasileira de Psicologia de Brasília), 9(1), 55-61.

17. Silveira, M. F., Matijasevich, A., Horta, B. L., Bettiol, H., Barbieri, M. A., Silva, A. A., Rondó, P. H. C., et al (2013). Prevalência de nascimentos pré-termo por peso ao nascer: revisão sistemática. Revista de Saúde Pública, 47(5), 992-1003.

18. Trevarthen, C. (1979). Communication and cooperation in early infancy. A description of primary intersubjectivity. In Bullowa, M. (Ed.), Before speech: The beginnings of human communication (pp. 321-347). London: Cambridge University Press.

19. Trevarthen, C. (2004). Learning about ourselves, from children: Why a growing human brain needs interesting companions? Scotland: University of Edinburgh,.

20. Trevarthen, C., \& Aitken, K. J. (2001) Infant intersubjectivity: Research, theory, and clinical applications. Annual Research Review. The Journal of Child Psychology and Psychiatry and Allied Disciplines, 42(1), 3-48.

21. Wanderlind, F., Martins, G. D. F., Hansen, J., Macarini, S. M., \& Vieira, M. L. (2006). Diferenças de gênero no brincar de crianças pré-escolares e escolares na brinquedoteca. Paidéia, 16(34), 263-273,

22. Wendland, E. (2001). A Abordagem clínica das interações pais-bebê: Perspectivas teóricas e metodológicas. Psicologia: Reflexão $e$ Crítica, 14(1), 45-56.

23. Wiese, E. B. P. (2009). O desenvolvimento do comportamento do bebê prematuro no primeiro ano de vida. Psicologia: Reflexão $e$ Crítica, 22(1), 76-85. 